\title{
Development of selection algorithms and databases for sea breeze studies
}

\section{Cesar Azorin-Molina, Sander Tijm \& Deliang Chen}

Theoretical and Applied Climatology

ISSN 0177-798X

Volume 106

Combined 3-4

Theor Appl Climatol (2011) 106:531-546 DOI 10.1007/s00704-011-0454-4

\section{Theoretical and Applied Climatology}

Vol. 91 No. 1-4 2008

SpringerWienNewYork

照 Springer 
Your article is protected by copyright and all rights are held exclusively by SpringerVerlag. This e-offprint is for personal use only and shall not be self-archived in electronic repositories. If you wish to self-archive your work, please use the accepted author's version for posting to your own website or your institution's repository. You may further deposit the accepted author's version on a funder's repository at a funder's request, provided it is not made publicly available until 12 months after publication. 


\title{
Development of selection algorithms and databases for sea breeze studies
}

\author{
Cesar Azorin-Molina • Sander Tijm • Deliang Chen
}

Received: 26 September 2010 / Accepted: 25 April 2011/Published online: 11 May 2011

(C) Springer-Verlag 2011

\begin{abstract}
We present an automated and manual algorithm for identifying past sea breeze episodes in the Bay of Alicante (southeastern coast of the Iberian Peninsula, IP, Spain) for a 6-year study period (2000-2005). The main goal was to provide databases for better understanding the functioning of sea breezes, which have a crucial influence on weather and climate in both coastal and inland areas and therefore affect human life in many ways. The algorithms apply a well-defined set of criteria based on meteorological and sea surface temperature measurements in order to detect past occurrences. The
\end{abstract}

\section{Azorin-Molina $(\bowtie)$}

Department of Geoenvironmental Processes and Global Change, Pyrenean Institute of Ecology (Spanish Research Council),

Avda. Montañana 1005,

50059 Zaragoza, Spain

e-mail: cazorin@ipe.csic.es

C. Azorin-Molina

Laboratory of Meteorology-Climatology, Mixed Unity CEAM-

UVEG, University Institute CEAM-UMH, Parque Tecnológico,

Charles R. Darwin 14,

46980 Paterna, Valencia, Spain

\section{S. Tijm}

Royal Netherlands Meteorological Institute (KNMI), 201, NL-3730 AE De Bilt, the Netherlands

D. Chen

International Council for Science (ICSU),

5 rue Auguste Vacquerie,

75116 Paris, France

D. Chen

Regional Climate Group, Department of Earth Sciences,

Göteborg University,

40530 Göteborg, Sweden automated and manual identification techniques successfully identified a total of 475 and 1414 sea breeze events, respectively. A large database containing the significant characteristic parameters measured (onset time, cessation time, duration time, maximum wind speed, inland penetration, etc.) for these 475 sea breeze days is presented. We evaluated the accuracy of both selection techniques by means of comparison with independent objective and subjective techniques. Both databases are the major contribution of this paper and have been used in some climatological sea breeze studies and are also presented here for any coastal expert interested in numerical-theoretical, observational-experimental and climatological wind studies.

\section{Introduction}

Methodologies and filter techniques for reliably identifying past sea breeze episodes are decisive in the construction of good quality databases aimed at gleaning greater knowledge of sea breezes. Over the last few decades, algorithms for the identification and forecasting of sea breezes have garnered much attention in the context of atmospheric research. Ramis et al. (1990) pointed out that few studies predict the occurrence of sea breezes. Hall (1954), Biggs and Graves (1962) and Lyons (1972) performed pioneering research work in the design of statistical forecasting techniques for lake breezes. Hall (1954) used a simple criterion based solely on the pressure difference between three sites in the State of Wisconsin (USA); nearly clear sky; light winds; and a centre of high pressure over Illinois. Biggs and Graves (1962) expounded a dimensional analysis based on an accurate lake breeze index which compares 
opposing background flows with the land-sea temperature difference:

$\sigma=\frac{V^{2}}{\left(C_{p} \Delta T\right)}$

where $V^{2}$ is the average hourly opposing wind speed (in metres per second) between $1000 \mathrm{~h}$ and $1600 \mathrm{~h}$ at an inland site; $C_{\mathrm{p}}$ is the specific heat coefficient of dry air at constant pressure $\left(1,003 \mathrm{~J} \mathrm{~kg}^{-1} \mathrm{~K}^{-1}\right) ; \Delta T$ is the difference (in Kelvin) between maximum inland air $\left(T_{1}\right)$ and lake surface water $\left(T_{\mathrm{w}}\right)$ temperatures; and $\sigma$ is an empirically derived constant called the lake breeze index. The index is a ratio of the controlling forces, i.e. the inertial and buoyancy forces, and was proposed for identifying lake breezes on the western shore of Lake Erie. Lyons (1972) improved the lake breeze index for the southwestern shore of Lake Michigan (Chicago, Illinois, USA) and used as the inertial force the geostrophic wind speed ( $V_{\mathrm{g}}$ in metres per second) at 12 UTC surface analysis:

$\sigma=\frac{V_{g}^{2}}{\left(C_{p} \Delta T\right)}=\frac{12.71 \times 10^{6}}{\left[\Delta N^{2}\left(T_{1}-T_{w}\right)\right]}$

where $\Delta N$ is the 4-mb isobar spacing (in kilometres) from the 06 UTC surface chart. For large index values, $V^{2}$ dominates and hence sea breezes will not develop in a situation of opposing winds. For small index values, $\Delta T$ is large and sea breezes are to be expected (Simpson 1994). Biggs and Graves (1962) and Lyons (1972) found critical values of $\sigma=3.0$ and $10.0 \mathrm{~m}^{2} \mathrm{~s}^{-2} \mathrm{~K}^{-1}$ for delineating days with and without lake breezes, respectively. Simpson (1994) reported an index value of $\sigma=7 \mathrm{~m}^{2} \mathrm{~s}^{-2} \mathrm{C}^{-1}$ for sea breezes at Thorney Island (UK). Other observational studies found different values of $\sigma$ (Miller and Keim 2003) in relation to techniques used for obtaining $V_{\mathrm{g}}$. Tijm (1999) defined a new sea breeze index which differs from that in Eq. 1. The method describes the sea breeze index as a function of the large-scale offshore component of the wind and the difference in surface layer sensible heat flux $\left(\Delta w^{\prime} \theta^{\prime}\right.$, in metre Kelvin per second) instead of the temperature difference. Porson et al. (2007) conducted a scaling analysis in order to develop an index for sea breeze speed and inland occurrence in a situation of offshore flows, similar to the Biggs and Graves index. These previous statistical forecasting techniques have been added to other diagram filters for the identification of past sea breeze events using routinely collected observations. For example, Steyn and Faulkner (1986) studied sea breezes in the lower Fraser Valley (Canada) applying the Biggs and Graves's method as a test criterion for finding past sea breeze episodes. Laird et al. (2001) found critical index values of $\sigma=2-6 \mathrm{~m}^{2} \mathrm{~s}^{-2} \mathrm{C}^{-1}$ and concluded that these forecasting techniques usually overpredict the number of sea breeze events and are difficult to apply to climatological datasets or for using large suites of data variables. A stochastic prediction scheme was proposed by Frysinger et al. (2003). This is the latest statistical sea breeze prediction algorithm based on wind and air temperature forecasts from synoptic models and observed sea surface temperature (SST) for Charleston (South Carolina, USA).

The current research focuses upon methodologies for identifying past sea breeze occurrences with the overall aim of creating multiyear high-quality databases for sea breeze studies. The particular aims of this paper were: (1) to present a background review on test criteria for selecting past sea breeze events; (2) to develop and evaluate accurate automated and manual filter techniques; and, principally, (3) to create two databases of past sea breeze days for numerical-theoretical, observational-experimental and climatological wind studies. The applications of both databases are also discussed here. The sea breeze datasets presented in this study are available for any expert interested in the meteorological modelling and climatological study of sea breezes.

\section{Background review of sea breeze methodology}

Table 1 summarises a background review concerning test criteria proposed in an attempt to establish a manual or objective selection method. The techniques are performed in order to ensure that the changes measured in meteorological variables were produced exclusively by sea breeze frontal passages (Ryznar and Touma 1981). The meteorological measurements employed are as follows:

1. Wind data: Surface wind speed (WS) and direction (WD) data are the most important meteorological variables with regard to distinguishing sea breezes. The passage of this local wind is characterized by a rapid shift in WS and WD from calm or light offshore winds to light to moderate onshore flows. The changes in WS and WD data from rawinsonde observations at $700 \mathrm{hPa}$ have also been used for rejecting synoptic-scale disturbances (Borne et al. 1998). In addition, Laird et al. (2001) employed average WS in the morning (0500-0700 LST) of $<5.5 \mathrm{~m} \mathrm{~s}^{-1}$ as an automated criterion for the identification of lake breeze events.

2. Air and sea surface temperature data: A positive temperature difference $(\Delta T)$ between air over the land and over the sea is the most prominent physical factor involved in the initiation of sea breezes (Gustavsson et al. 1995). Whilst air temperature data over seas or lakes are still quite sparse and not always consistent, most studies use SST for computing this objective criterion. A decrease in diurnal air temperature development is also a particular sea breeze feature used as a selection filter. 
Table 1 Background review of overall test criteria used for both automated and manual methodologies for detecting sea or lake breezes

\begin{tabular}{|c|c|c|c|c|c|c|c|c|c|c|c|}
\hline References & Test 1 & Test 2 & Test 3 & Test 4 & Test 5 & Test 6 & Test 7 & Test 8 & Test 9 & Test 10 & Test 11 \\
\hline Biggs and Graves (1962) & $\checkmark$ & $\checkmark$ & & & & & & & & & \\
\hline Lyons (1972) & $\checkmark$ & $\checkmark$ & & $\checkmark$ & & & $\checkmark$ & & & & \\
\hline Barbato (1978) & $\checkmark$ & & $\checkmark(b)$ & & $\checkmark$ & & $\checkmark$ & & & & \\
\hline Brittain (1978) & & $\checkmark$ & & & & & & & & & \\
\hline Ryznar and Touma (1981) & $\checkmark$ & & $\sqrt{ }(\mathrm{b})$ & $\checkmark$ & $\checkmark$ & $\checkmark$ & & & & & \\
\hline Prezerakos (1986) & $\checkmark$ & & $\checkmark$ & $\checkmark$ & & & & & & & \\
\hline Steyn and Faulkner (1986) & $\checkmark$ & $\checkmark$ & & & & & $\checkmark$ & & & & \\
\hline Banfield (1991) & $\checkmark$ & & & & & & & & & & \\
\hline Redaño et al. (1991) & $\checkmark$ & & $\checkmark$ & $\checkmark$ & & & & & & & \\
\hline Gustavsson et al. (1995) & $\checkmark$ & & $\checkmark(b)$ & & $\checkmark$ & $\checkmark$ & & & & & \\
\hline Borne et al. (1998) & $\checkmark(\mathrm{a})$ & $\checkmark$ & & & & & & & & & \\
\hline González et al. (1998) & & & & & & & & & & $\checkmark$ & \\
\hline Tijm (1999) & & & & & & & & & $\checkmark$ & & \\
\hline Laird et al. (2001) & $\checkmark$ & $\checkmark$ & & & & & & & & & \\
\hline Furberg et al. (2002) & $\checkmark$ & $\checkmark$ & & & & & & & & & \\
\hline Miller and Keim (2003) & $\checkmark$ & & $\sqrt{ }(\mathrm{b})$ & $\checkmark$ & & & & $\checkmark$ & & & \\
\hline Salvador and Millán (2003) & $\checkmark$ & $\checkmark$ & $\sqrt{ }(\mathrm{b})$ & & & & & & & & \\
\hline Steyn (2003) & & & & & & & & & $\checkmark$ & & \\
\hline Bowers (2004) & $\checkmark$ & & & & $\checkmark$ & $\checkmark$ & & & & & \\
\hline Prtenjak and Grisogono (2007) & $\checkmark$ & $\checkmark$ & & $\checkmark$ & & & & & & & $\checkmark$ \\
\hline Azorin-Molina and Lopez-Bustins (2008) & & & $\checkmark$ & & & & & & & & \\
\hline
\end{tabular}

Test 1: rapid shift in WS and WD at surface or upper levels (denoted by letter a); Test 2: $\Delta T$ land-sea-air; Test 3: weak surface pressure gradient. Synoptic weather chart (denoted by letter b); Test 4: cloudiness; Test 5: decrease in TEMP; Test 6: increase in RH; Test 7: hours of sunshine; Test 8: PCPN or thunder report; Test 9: $\Delta w^{\prime \prime}$; Test 10: overall wind convergence; Test 11: air PRES amplitude

3. Air humidity data: An increase in vapour pressure or air relative humidity a short time after sea breeze frontal passage has been used as a follow-up criterion for selecting past sea breezes from meteorological measurements.

4. Air pressure data: A weak pressure gradient at surface level is a primary condition for the onset of local winds. Manual revision of synoptic weather charts and computation of diurnal air pressure amplitude (Prtenjak and Grisogono 2007) have been used to exclude days influenced by the passing of frontal or baric systems.

5. Total cloudiness and hours of sunshine data: The presence of nearly clear skies, which must usually be $<4$ / 8 (Prezerakos 1986), and therefore a large percentage of hours of sunshine enhances the development of sea breezes.

6. Precipitation data: This meteorological measurement serves as an additional parameter for detecting an unstable atmosphere accompanied by overcast skies and rain showers, which prevent sea breeze development. Miller and Keim (2003) used a test criterion based on unappreciable precipitation (one or two brief light showers were permissible) within the 6-h period prior to the onset of sea breezes.

\section{Measurements and study area}

The province of Alicante is located on the southeast fringe of the Iberian Peninsula (IP, south of the Valencia region), as well as in the Western Mediterranean basin. The Bay of Alicante was chosen because of the key role played by sea breezes and the lack of research in relation to this subject in this area. Most sea and lake breeze studies have obtained data during rather short surface observations (i.e. less than or around 6 years; Laird et al. 2001). Therefore, the 6-year study period used here represents a reasonable but laborious task for the application of a detailed manual revision on a daily basis.

Figure 1 shows the study area, which corresponds to the Bay of Alicante and the surrounding district called Campo de Alicante: a coastal plain where the Prebetic mountain ranges (1000-1600 $\mathrm{m}$ of height) are located between 10 and $15 \mathrm{~km}$ inland. Thermally-driven flows on heated slopes of low steepnees may couple with sea breezes increasing horizontal and vertical wind speeds and an earlier inland sea breeze frontal passage. In contrast, a heated slope of high steepness will block the inland propagation of sea breezes and decrease the horizontal and vertical wind speeds as reviewed Crosman and Horel (2010). The blocking of the 
Fig. 1 Map of the province of Alicante showing the Bay of Alicante and locations of the $\mathrm{RS}$, the CJ and the SST measurement site (Albufereta beach). The inset photographs correspond to the surface weather observation reference station at the Laboratory of Climatology of the University of Alicante (a), the automatic recording station with the wind cup and wind wane at the righthand end of a cross beam (b) and the mechanical wind recorder or anemograph (c). Sea and land breeze central axes with respect to the coastline are given in the lower central part

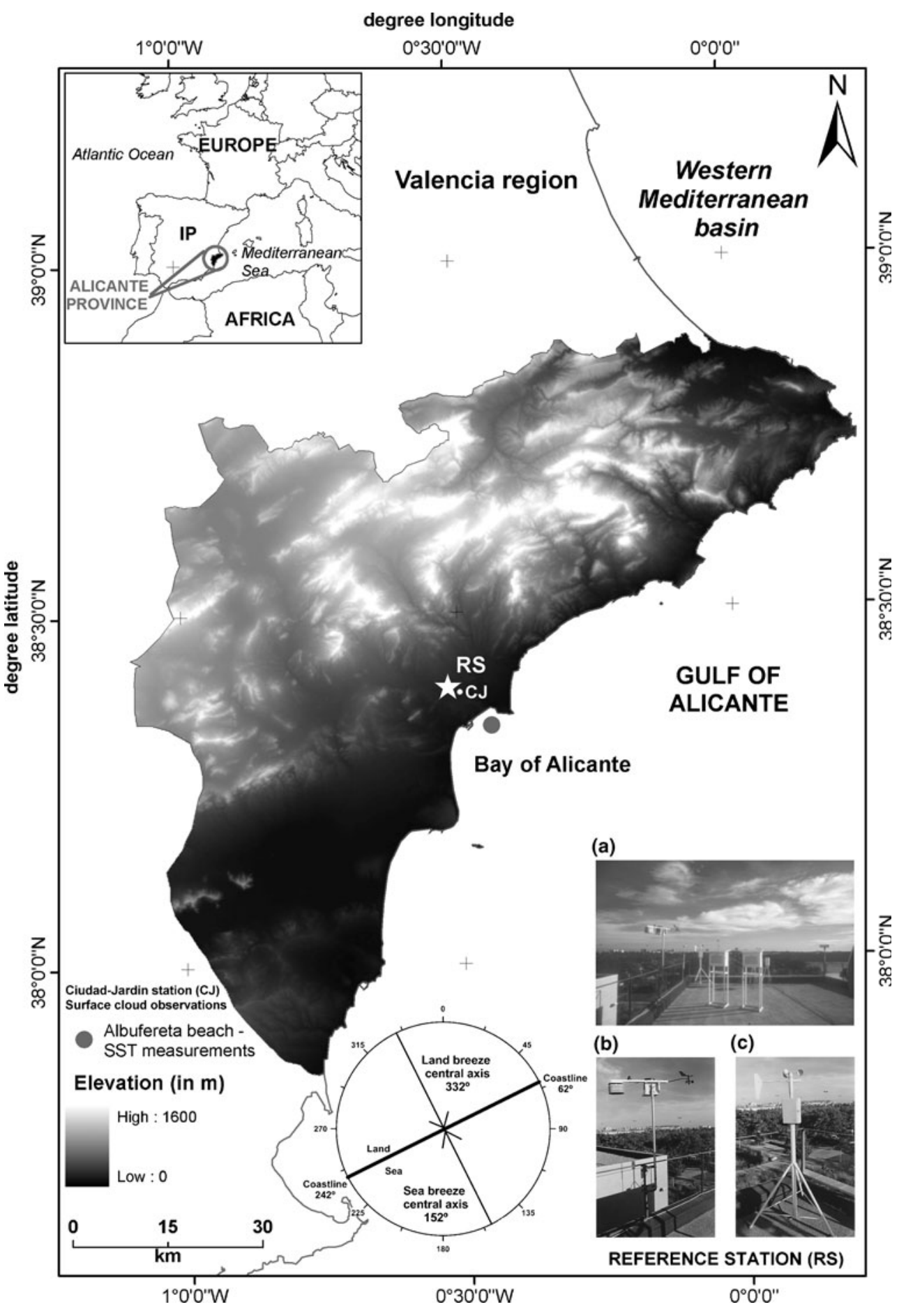

flow by the mountain ranges will have some impact on the local winds in the study area.

The primary procedure in which to objectively or subjectively select past sea breezes involved the routine collection of surface observations. The automatic meteorological station situated at the Laboratory of Climatology of the University of Alicante $\left(38^{\circ} 23^{\prime} \mathrm{N}, 0^{\circ} 31^{\prime} \mathrm{W}, 102 \mathrm{~m}\right.$ above sea level and $5.1 \mathrm{~km}$ from the shore belonging to the University Institute of Geography; http://www.labclima.ua.es) was cho- sen as the reference synoptic station (hereafter RS) for sea breeze studies. The 30-min observations of WS (in metres per second) and WD (in degrees and stored in $1^{\circ}$ steps); temperature (TEMP, in degree Celsius); relative humidity (RH, in per cent); pressure (PRES, in millibars or hectopascals); and precipitation (PCPN, in millimetres) were used here over a 6-year study period (2000-2005). The WS and WD data, as well as all meteorological variables, were collected at a height of $10 \mathrm{~m}$. Additional data from a 
mechanical wind recorder or anemograph, a thermohygrograph and a rain gauge were used to fill missing values in half-hourly data, which are $<5 \%$. Finally, the sunrise and sunset times were calculated for each day applying the Ortocaso software programmed by the Spanish Meteorological Agency (AEMET).

Monthly SST measurements were acquired from the Institute of Coastal Ecology of El Campello (http://www. ecologialitoral.com/). The SST data are measured $0.4 \mathrm{~km}$ offshore and at a bathymetric elevation of 4-5 $\mathrm{m}$ on the Albufereta beach $\left(38^{\circ} 21^{\prime} \mathrm{N}, 0^{\circ} 26^{\prime} \mathrm{W}\right)$. This location is $6.3 \mathrm{~km}$ to the RS site. Daily SST data were computed by linearly interpolated values from monthly measurements. This is the most reliable SST data given that 1-h TEMP data from the nearest buoy have been available since July 2006 (Cabo de Palos buoy; 37³9' N, $0^{\circ} 19^{\prime} \mathrm{W}$; http://www.puertos.es/es/ oceanografia_y_meteorologia/redes_de_medida/index.html).

Total cloud cover (amount in eights) collected at the Alicante-Ciudad Jardin synoptic station (CJ; $38^{\circ} 22^{\prime} \mathrm{N}$, $00^{\circ} 29^{\prime} \mathrm{W} ; 82 \mathrm{~m}$ above sea level and $3.3 \mathrm{~km}$ from the shore; AEMET) in January, April, July and November 2004 enabled us to apply an independent automated selection technique in Section 5.

\section{Sea breeze selection algorithms}

\subsection{Methodology design}

The interaction of sea breezes with factors at synoptic scale, local spatial scale and at mesoscale hinders the design of an accurate methodology. Basically, the accuracy of the past sea breeze days selected depends on the (a) objectives of the study; (b) definition of a sea breeze episode by each researcher (i.e. sea breezes or sea and land breeze cycles); (c) available data and test criteria used; and (d) features of the study area.

Previous empirical knowledge of sea breezes were acquired in the Bay of Alicante by means of extensive fieldwork (Olcina-Cantos and Azorin-Molina 2004). The geometry of the coastline is considered to define the central sea and land breeze axes (Gustavsson et al. 1995; Furberg et al. 2002; Prtenjak and Grisogono 2007). The local orientation of the shoreline adjacent to the RS is assumed to be $62.0^{\circ}-242.0^{\circ}$ (Fig. 1) despite the concave land-water boundary of the Bay of Alicante. The sea and land breeze central axes are therefore $152.0^{\circ}$ and $332.0^{\circ}$, respectively. However, observational campaigns detected that the local geometry and topography of the coastline cause certain changes in the direction of sea breezes (Miao et al. 2003). Consequently, sea breezes blow in the range from $45.0^{\circ}$ to $180.0^{\circ}$, and the Coriolis force (Neumann 1984) can produce sea breezes from $180.0^{\circ}$ to $225.0^{\circ}$ in the late evening, i.e. almost parallel to the coastline. Land breezes (not regarded in this study) usually blow from $247.5^{\circ}$ to $22.5^{\circ}$. Brief transitions periods (Salvador and Millán 2003) occur between sea and land breeze passages. These are defined by a 30 -min mean WS of $<1.5 \mathrm{~m} \mathrm{~s}^{-1}$ or a WD which is usually from $23.0^{\circ}$ to $44.0^{\circ}$ or from $181.0^{\circ}$ to $247.0^{\circ}$.

\subsection{Manual selection algorithm}

Figure 2a shows the flow diagram of the manual selection filters proposed for the identification of past sea breeze events for the 6-year study period (2000-2005). The manual procedure chooses tests $1,5,6$ and 8 tabulated in Table 1 and discussed in Section 2. The examination of the daily time series (graphs and databases) of 30-min observations of WS, WD, TEMP, RH and PCPN was considerably laborious. The following six empirical criteria need to be accomplished in order to detect sea breeze passages (filters 1 to 3 ) and to confirm (filters 4 to 6 ) a sea breeze event:

Filter 1: The $\mathrm{WS}_{\mathrm{x}}$ and $\mathrm{WS}_{\max }$ curves present a steady increase from after sunrise until noon, and a gradual decrease occurs from afternoon until sunset. $\mathrm{WS}_{\mathrm{x}}$ and $\mathrm{WS}_{\max }$ are the 30-min mean and maximum WS, respectively.

Filter 2: $\mathrm{WD}_{\mathrm{x}}$ ranges from $45.0^{\circ}$ to $180.0^{\circ}$, i.e. onshore flows after sunrise. $\mathrm{WD}_{\mathrm{x}}$ is the 30 -min mean WD. The landward-moving wind shift is a distinctive feature that practically ensures stable synoptic conditions with weak large-scale flows and positive $\Delta T$ values.

Filter 3: $\quad D_{\mathrm{t}}$ of sea breezes must be $\geq 2 \mathrm{~h} . D_{\mathrm{t}}$ is the duration of onshore flows detected during the daytime.

The change in WS is applied as filter 1 as nocturnal offshore winds (land breezes) do not usually blow in summer months over the Bay of Alicante because probably the cooling is not so strong (Azorin-Molina 2007). In these cases, sea breeze passages are not associated with a reversal in WD, but rather with a typical increase in WS as a function of positive $\Delta T$ values. Most experts state that nocturnal offshore large-scale flows are required in order to identify true sea breeze passages, a requirement that is not satisfied with regard to finding sea breezes in the Bay of Alicante. Moreover, large-scale onshore flows can be removed manually because ambient winds are moderate to strong and blow without a gradual veering.

Filter 4: $\leq$ TEMP $_{\mathrm{x}}$ after initiation of sea breezes, where TEMP $_{\mathrm{x}}$ is the 30 -min mean TEMP, i.e. an abrupt decrease in the diurnal air temperature curve.

Filter 5: $\geq \mathrm{RH}_{\mathrm{x}}$ after initiation of sea breezes, where $\mathrm{RH}_{\mathrm{x}}$ is the 30-min mean RH, i.e. an abrupt increase in the diurnal relative humidity curve. 

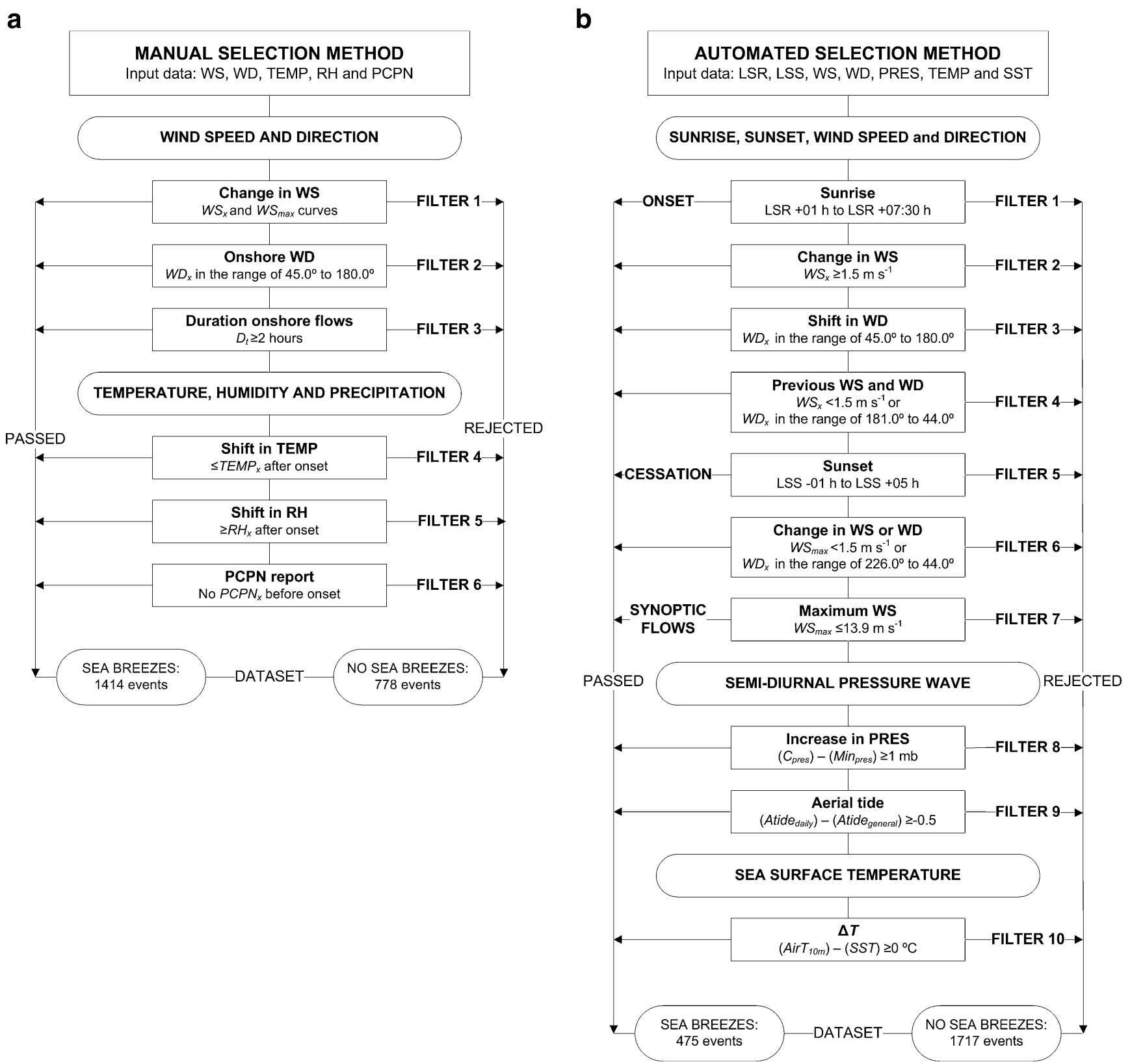

Fig. 2 a Flow diagram showing filters employed in the manual selection methodology for finding past sea breeze episodes for the 6-year study period (2000-2005). Acronyms are defined in the text. b As in a, except for the automated selection methodology

Filter 6: No $\mathrm{PCPN}_{\mathrm{x}}$ is measured prior to the onset of sea breezes, where $\mathrm{PCPN}_{\mathrm{x}}$ is the 30 -min amount of PCPN.

A stabilization and a slight downward inflection of TEMP curves and a stabilization and an upward inflection of RH curves are other features for finding sea breezes. These changes are not exclusive to sea breezes since they can also be caused by large cumulus clouds shading the sun on a warm day (Ryznar and Touma 1981). However, cloudinduced changes do not meet the requirement filters 1 to 3 . A few hours after sea breeze initiation (usually in the afternoon), some reports of PCPN might be associated with the development of sea breeze fronts and thunderstorms, and those days were therefore not removed.

If the requirements of manual filters 1 to 6 were not met, the day was excluded entirely from the dataset. The manual method discretizes meteorological data into two categories: (a) sea breezes ( $\mathrm{SB}$ ) and (b) non-sea breezes (NSB).

\subsection{Automated selection algorithm}

Figure $2 \mathrm{~b}$ displays the flow diagram of the objective computerbased filters proposed for identifying past sea breeze episodes 
for the 6-year study period (2000-2005). The automated procedure chooses tests 1,2 and 11 tabulated in Table 1 and discussed in Section 2. Apart from surface WS, WD and TEMP measurements, we also used 30-min observations of PRES, daily SST, as well as local sunrise (LSR) and sunset (LSS) data (in UTC) from the RS. The LSR and LSS data were employed in order to ensure the selection of sea breezes within a complete diurnal cycle. The automated selection diagram is made out of ten filters in order to accurately detect sea breezes and create a database for sea breeze studies. The filters are grouped into two main categories: (a) distinctive features in WS and WD, and (b) physical processes of sea breezes. The first filter group employs the characteristic rapid shift in WS and WD, which is the most important feature in the use of surface meteorological measurements, in order to detect the onset (filters 1 to 4 ) and cessation (filters 5 and 6) of sea breezes and to reject moderate to strong onshore largescale flows (filter 7).

Filters 1 to 4: $\mathrm{LSR}+0100$ hours to $\mathrm{LSR}+0730$ hours (UTC). The onset is defined by the sea breeze passage between 0100 hours (i.e. summer months) and 0730 hours (i.e. winter months) after LSR (filter 1). The onset occurs when the $\mathrm{WS}_{\mathrm{x}}$ is $\geq 1.5 \mathrm{~m} \mathrm{~s}^{-1}$ (filter 2; Salvador and Millán 2003), which ensures that sea breezes are completely established, and $\mathrm{WD}_{\mathrm{x}}$ ranges from $45.0^{\circ}$ to $180.0^{\circ}$ (filter 3 ) simultaneously. Previous $\mathrm{WS}_{\mathrm{x}}$ and $\mathrm{WD}_{\mathrm{x}}$ must be $<1.5 \mathrm{~m} \mathrm{~s}^{-1}$ or from $181.0^{\circ}$ to $44.0^{\circ}$ (filter 4), respectively. The $\mathrm{WS}_{\mathrm{x}}$ is established as an initial condition in filter 4 as land breezes do not usually blow in summer months, as has been stated above. The onset time $\left(O_{\text {time }}\right)$, onset lag $\left(O_{\text {lag }}\right)$, onset speed $\left(O_{\mathrm{ws}}\right)$ and onset direction $\left(O_{\mathrm{wd}}\right)$ were tabulated in the database presented in Section 4.4.

Filters 5 and 6: LSS -0100 hours to LSS +0500 hours (UTC). The cessation is defined by the sea breeze front retreat between 0100 hours (i.e. winter months) before and 0500 hours (i.e. summer months) after LSS (filter 5). The cessation occurs when $\mathrm{WS}_{\max }$ is $<1.5 \mathrm{~m} \mathrm{~s}^{-1}$ or the $\mathrm{WD}_{\mathrm{x}}$ is from $226.0^{\circ}$ to $44.0^{\circ}$ (filter 6). $\mathrm{WS}_{\max }$ was employed instead of $\mathrm{WS}_{\mathrm{x}}$ as it best represents sea breeze cessation. Albeit infrequently, the $\mathrm{WS}_{\mathrm{x}}$ of sea breezes can be lower than $1.5 \mathrm{~m} \mathrm{~s}^{-1}$, and sea breeze retreats would therefore be detected too early. $\mathrm{WS}_{\max }$ constitutes a reasonably reliable test for establishing the cessation of sea breezes. As in filter $4, \mathrm{WD}_{\mathrm{x}}$ constitutes a secondary criterion as reversal wind change from onshore to offshore direction does not always occur at the end of the day. Cessation time $\left(C_{\text {time }}\right)$ and cessation lag $\left(C_{\text {lag }}\right)$ were also computed in the database.

Filter 7: $\quad \mathrm{WS}_{\max } \leq 13.9 \mathrm{~m} \mathrm{~s}^{-1}$. Sea breeze gust intensities rarely rise above $14.0 \mathrm{~m} \mathrm{~s}^{-1}$ in the Bay of Alicante (Azorin-Molina et al. 2011). We calculated the $\mathrm{WS}_{\max }$ for each sea breeze episode for the database.

The second filter group uses two novel filters based on semi-diurnal pressure waves in combination with a positive $\Delta T$. The pressure field is of primary importance as it supplies the driving force for low-level sea breeze development (Simpson 1994). This thermal wave is caused by temperature variation in the boundary layer of the atmosphere, which differs from land to sea. Figure 3 represents the mean atmospheric tide in the RS for the 6-year study period, showing a regular daily variation: a maximum at 1000 hours $(1018.0 \mathrm{mb})$ and a minimum at 1600 hours (1016.2 mb), with a second maximum at 2200 hours $(1017.8 \mathrm{mb})$ and a second minimum at 0400 hours (1016.9 mb), of lower amplitude. Van Delden (1993) and Tijm and Van Delden (1999) conducted in-depth research of the role played by sound waves in the onset of sea breezes using a linear numerical model. Furthermore, some investigations (Millán 2002) emphasise the important role played by the diurnal thermal low developing over the centre of the IP, resulting from diabatic heating (Simpson 1994; Tijm 1999), and favours sea breeze circulations in the summer months. Prtenjak and Grisogono (2007) have been

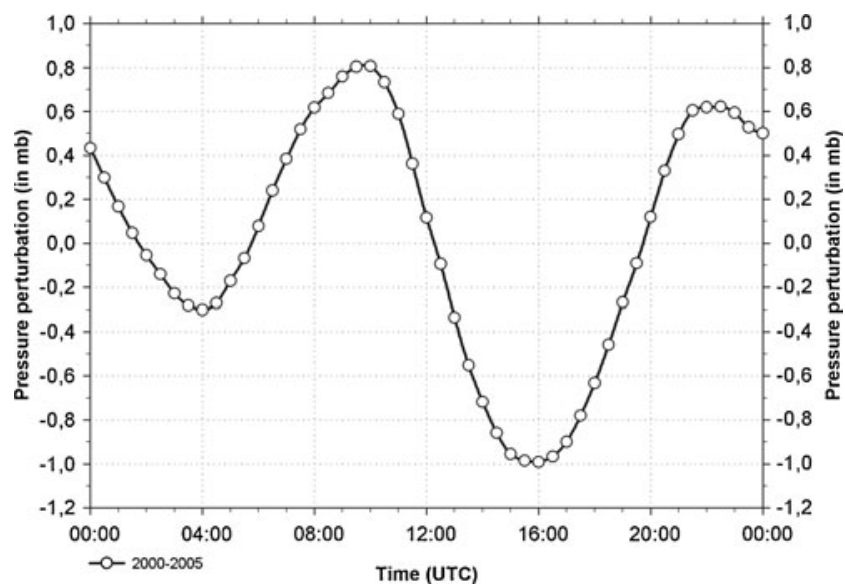

Fig. 3 Daily cycle of the surface pressure perturbation from the 30min mean surface pressure at the RS for the 6-year study period (2000-2005) 
the only researchers (Table 1) to employ surface pressure data (diurnal pressure amplitude $<5 \mathrm{hPa}$ ) as a selection test. The identification of the thermal wave was used here as an alternative criterion for selecting calm weather conditions with no appreciable synoptic changes or large-scale flows, which generally disturb sea breezes. Filters 8 and 9 were used to ensure the detection of the daily aerial tide at the RS.

Filter 8: $\quad\left(C_{\text {pres }}\right)-\left(\operatorname{Min}_{\text {pres }}\right) \geq 1 \mathrm{mb}$, where $C_{\text {pres }}$ is the PRES at the time of cessation of sea breezes and $\mathrm{Min}_{\text {pres }}$ is the minimum PRES measured from $O_{\text {time }}$ to $C_{\text {time. }}$. The filter test detects the increase in PRES between the minimum around 1600 hours and the secondary maximum at 2200 hours. The threshold for this criterion was set to $\geq 1 \mathrm{mb}$.

Filter 9: $\quad\left(\right.$ Atide $\left._{\text {daily }}\right)-\left(\right.$ Atide $\left._{\text {general }}\right) \geq-0.5$, where Atide $_{\text {daily }}$ and Atide general $_{\text {are the semi- }}$ diurnal pressure waves for each sea breeze day selected by the first filter group and for the 6-year study period (Fig. 3), respectively. The threshold value (greater than or equal to -0.5 ) was found the same as filter 8 . The most negative values (less than -0.5 ) represent days with noteworthy synoptic changes and were therefore rejected. The Atide daily $_{\text {and }}$ Atide general values were computed as follows:

Atide $=(\mathrm{P} 10+\mathrm{P} 22)-(\mathrm{P} 04-\mathrm{P} 16)$

where P04, P10, P16 and P22 are the PRES at 0400, 1000, 1600 and 2200 hours UTC, respectively. The Atide general $_{\text {from values }}$ plotted in Fig. 3 resulted in 2.72.

Finally, the $\Delta T$ provides the local forcing for the development of sea breezes (Simpson 1994). The comparison of the mean monthly maximum and minimum air TEMP with the corresponding SST curve for the 6-year period have been plotted in Fig. 4. The mean monthly SST curve is below the mean monthly maximum air TEMP, and sea breezes are therefore likely to be triggered throughout the whole year. April and June have the biggest $\Delta T$ $\left(4.4^{\circ} \mathrm{C}\right)$, whereas the smallest $\Delta T$ are found in September $\left(0.9^{\circ} \mathrm{C}\right)$ and December $\left(1.3^{\circ} \mathrm{C}\right)$. The $\Delta T$ was employed as a last filter as daily SST data interpolated from monthly data were used. This criterion, which does not require large temperature differences (Laird et al. 2001; Segal and Pielke 1985; Arritt 1987; Simpson 1994), was formulated as follows:

Filter 10: $\quad\left(\operatorname{AirT}_{10 \mathrm{~m}}\right)-(\mathrm{SST}) \geq 0$, where $\operatorname{AirT}_{10 \mathrm{~m}}$ is the screen daily maximum air temperature at the RS.

The automated method distinguishes between (a) SB days when the ten filters are fulfilled and (b) NSB events, when at least one requirement is not satisfied.

\subsection{Sea breeze databases and applications}

Table 2 displays a summary of the monthly number $(N)$ and probability $\left(P_{1}=[1] / N\right)$ of sea breeze episodes identified by both automated and manual selection algorithms for the 6-year study period. A subset of 475 and 1414 sea breeze events was identified in the RS by means of the automated and manual techniques, respectively. The objective method found only one third of sea breezes selected by the subjective diagram, which means that the applications of both datasets for sea breeze studies must be different. The objective and subjective natures of the automated and manual methods create a margin of error that tends to strongly underestimate and slightly overestimate the results, respectively.

The manual selection technique does not demand information on the $O_{\text {time }}$ and $C_{\text {time }}$ of sea breezes. Figure 5 illustrates five typical sea breeze situations as sea breeze events without land breezes at night (Fig. 5a). The subjective method correctly counts late afternoon initiations when moderate to strong offshore synoptic winds are weakened during the morning hours (Lyons 1972; Fig. 5b); early evening cessations when outflows from well-developed thunderstorms interrupt sea breezes (Hewson and Moroz 1966; Fig. 5c); increase of Strocumulus clouds over the area,

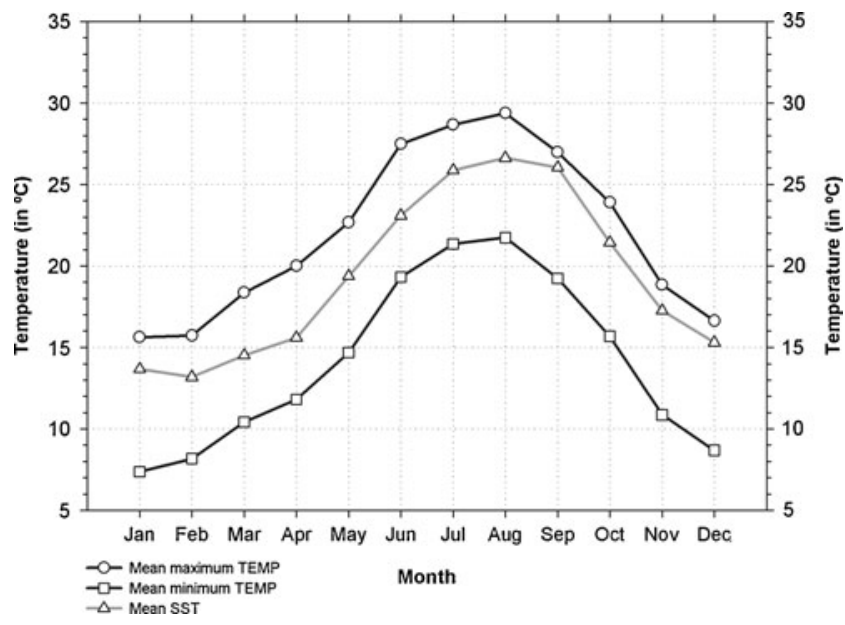

Fig. 4 Mean monthly maximum and minimum air TEMP at the RS and mean monthly SST at the Albufereta beach for the 6-year study period (2000-2005) 


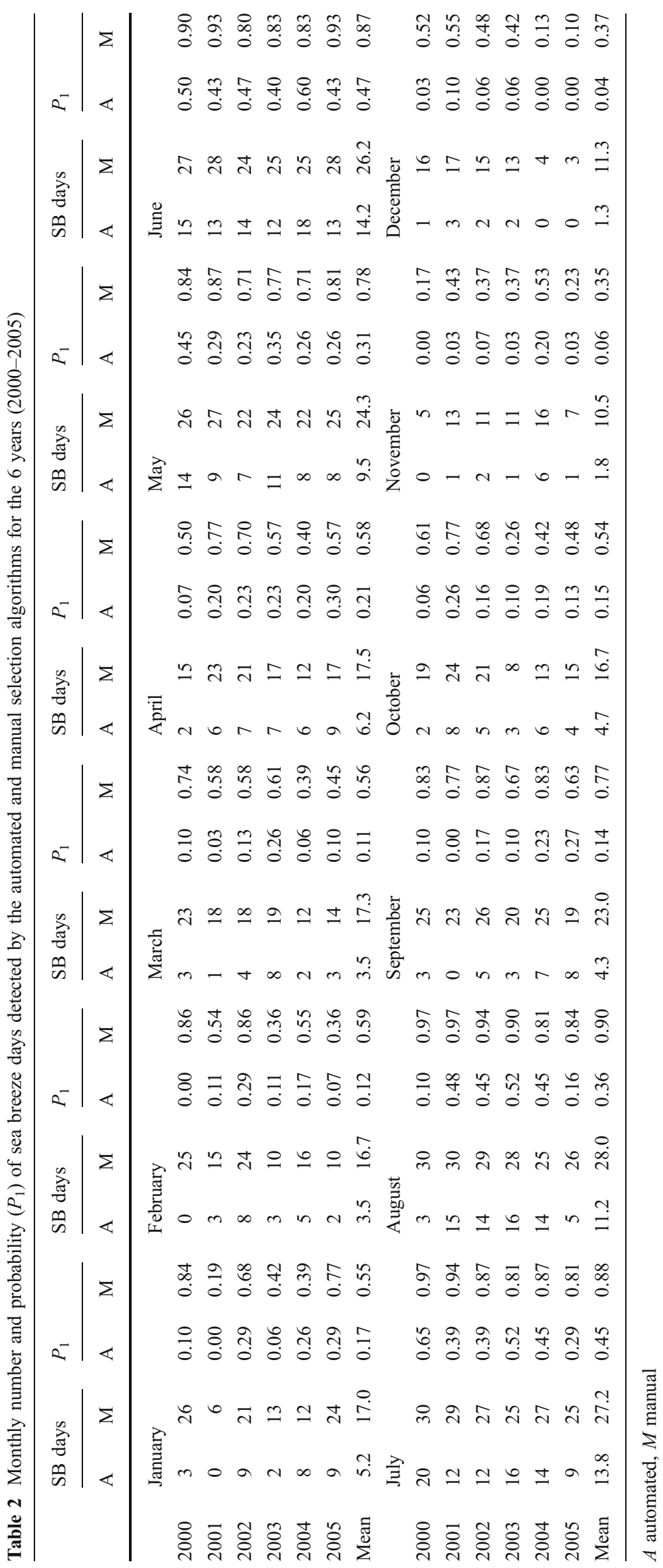


a

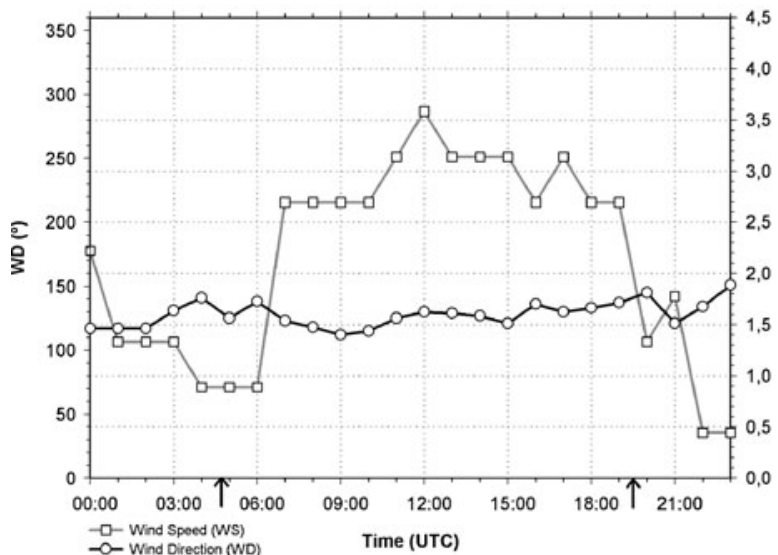

b

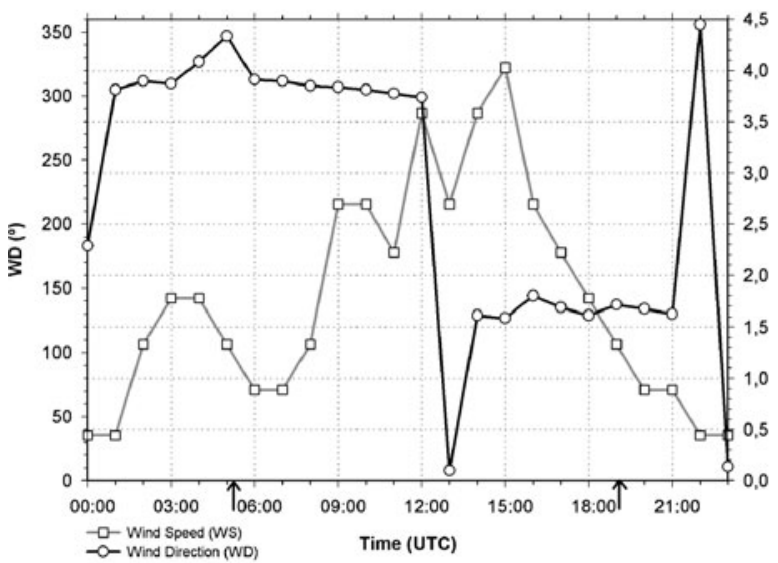

C

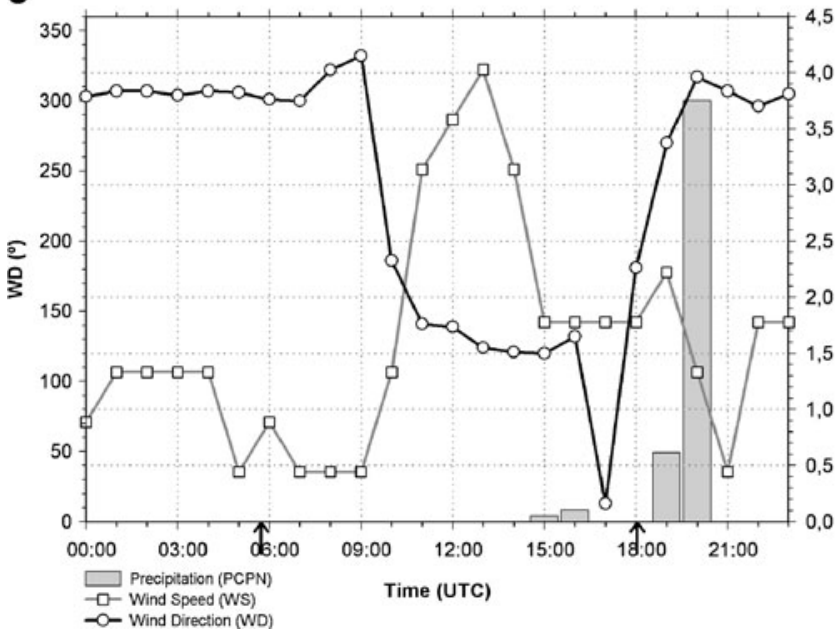

Fig. 5 WS, WD and PCPN for typical sea breeze situations illustrating discrepancies between the manual and automated selection methods: a sea breeze event without land breezes at night (3rd July 2004, selected by both methods); b late afternoon initiation (11th August 2005, selected by the manual method); c early evening

which brings down the $\Delta T$ and therefore weakens sea breezes (Fig. 5d); and a strengthening of sea breezes by the d

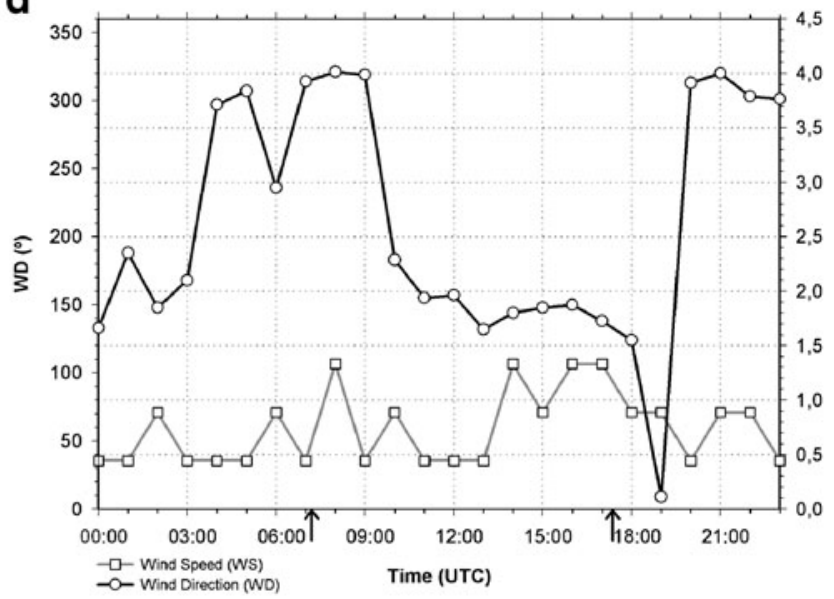

e

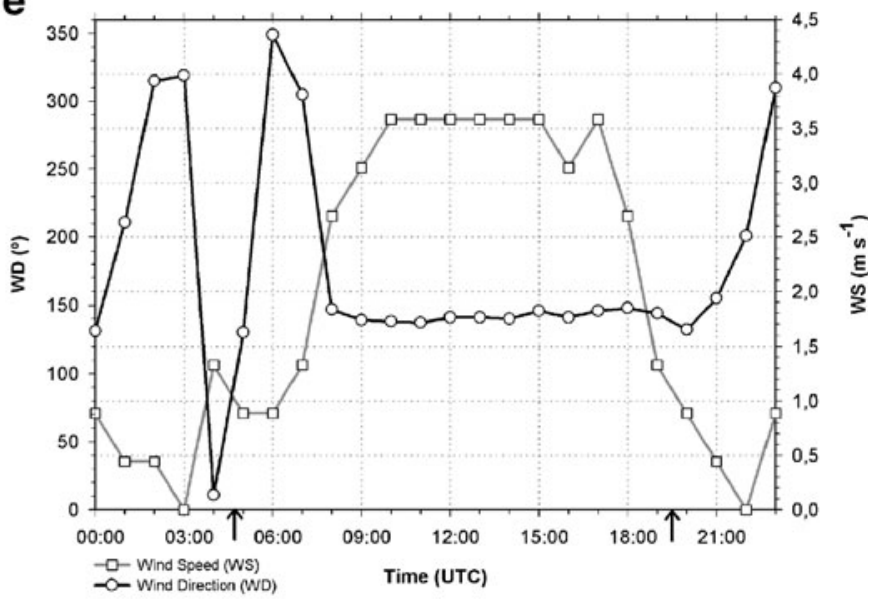

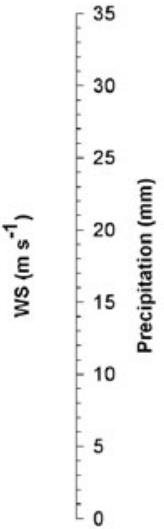

cessation (21st September 2002, selected by the manual method); d increased low cloudiness (3rd February 2004, selected by the manual method); e strengthening of a sea breeze episode (3rd July 2003, selected by the manual method). Small arrows show hours of sunrise and sunset (in UTC)

coupling of onshore large-scale winds (Fig. 5e), among many other non-pure sea breeze situations. We therefore 
took sea breezes in complete and incomplete diurnal cycles into account. Consequently, the sea breeze dataset constructed by means of the manual selection technique potentially enabled the study of the daily occurrence and persistence of sea breezes in the Bay of Alicante (AzorinMolina and Martin-Vide 2007). The high occurrence of sea breezes and persistence of sea breeze spells is the main factor controlling air pollution dynamics and problems of air quality in Mediterranean cities. This database is being used by the Programme of Atmospheric Pollution at the University Institute CEAM-UMH (http://www.ceam.es/). Nevertheless, this subset is not useful for the study of the main sea breeze parameters and physical factors controlling this local wind because non-pure sea breeze events disturb mean statistics.

The automated selection method removes the synoptic influence and the other aforementioned disturbing factors. The objective algorithm has the added capacity to distinguish most sea breeze events in a complete diurnal cycle. The selection technique was designed to use a set of seven tests in the first filter group in order to increase accuracy and to construct a sea breeze database. Table 3 shows the magnitudes of the main sea breeze characteristics and other parameters from 2nd to 8th June 2005. The sea breeze dataset constructed by means of the automated procedure has enabled the mean characteristics (Azorin-Molina et al. 2009, 2011) and physical factors (Azorin-Molina and Chen 2009) of sea breezes to be studied. The data compiled in the Table 3 could serve to validate whether meteorological models accurately represent the sea breeze characteristics observed.

\section{Validity of the sea breeze selection algorithms}

The accuracy of the manual and automated selection methods was evaluated by means of comparison with an independent subjective and objective technique, respectively. The SB and NSB events selected by the proposed (subscript "p") techniques and the independent (subscript "i") methods are set into a matrix similar to that of Laird et al. (2001). We computed four calculations from the matrix taking the number of the equal $\left(\mathrm{SB}_{\mathrm{p}} \mathrm{SB}_{\mathrm{i}}\right.$ and $\left.\mathrm{NSB}_{\mathrm{p}} \mathrm{NSB}_{\mathrm{i}}\right)$ and different $\left(\mathrm{SB}_{\mathrm{p}} \mathrm{NSB}_{\mathrm{i}}\right.$ and $\left.\mathrm{NSB}_{\mathrm{p}} \mathrm{SB}_{\mathrm{i}}\right)$ detections. The probabilities calculated range from 0 to 1 , where 1 indicates the equal or different detections of sea and non-sea breeze events.

(a) Probability of equal detections of sea breezes $\left(\mathrm{PSB}_{\mathrm{p}} \mathrm{SB}_{\mathrm{i}}\right)$ : The number of equal detections of sea breezes divided by the total number of sea breezes selected by both methods.

$$
P S B_{p} S B_{i}=\frac{S B_{p} S B_{i}}{S B_{p} S B_{i}+S B_{p} N S B_{i}+N S B_{p} S B_{i}}
$$

(b) Probability of equal detections of non-sea breezes $\left(\mathrm{PNSB}_{\mathrm{p}} \mathrm{NSB}_{\mathrm{i}}\right)$ : The number of equal detections of non-sea breezes divided by the total number of nonsea breezes selected by both techniques.

$$
P N S B_{p} N S B_{i}=\frac{N S B_{p} N S B_{i}}{N S B_{p} N S B_{i}+S B_{p} N S B_{i}+N S B_{p} S B_{i}}
$$

(c) Probability of different detections of sea breezes $\left(\mathrm{PSB}_{\mathrm{p}} \mathrm{NSB}_{\mathrm{i}}\right)$ : The number of different detections of sea breezes, i.e. sea breezes detected by the proposed method and non-sea breezes selected by the independent technique, divided by the total number of different detections of sea breezes.

$$
P S B_{p} N S B_{i}=\frac{S B_{p} N S B_{i}}{S B_{p} N S B_{i}+N S B_{p} S B_{i}}
$$

(d) Probability of different detections of non-sea breezes $\left(\mathrm{PNSB}_{\mathrm{p}} \mathrm{SB}_{\mathrm{i}}\right.$ ): The number of different detections of sea breezes, i.e. non-sea breezes detected by the proposed method and sea breezes selected by the independent technique, divided by the total number of different detections of sea breezes.

$$
P N S B_{p} S B_{i}=\frac{N S B_{p} S B_{i}}{S B_{p} N S B_{i}+N S B_{p} S B_{i}}
$$

The independent manual selection technique was performed by an experienced sea breeze researcher from the Regional Climate Group (http://rcg.gvc.gu.se/) of the University of Göteborg (Sweden). The 30-min observations of surface WS, WD, TEMP, RH and PCPN recorded in the RS were used by this researcher who defined her own filters for finding sea breeze passages. The months of January, April, July and November 2004 were chosen for the evaluation because they cover the four seasons. The characteristics of sea breezes vary throughout the year and should therefore influence manual sea breeze detection. For comparison between the proposed manual method and the independent Regional Climate Group technique (hereinafter RCG method), days were also classified into the two categories (SB and NSB) described above. A SB event groups the "sea breeze" and "possible sea breeze" categories defined by Borne et al. (1998) without using $\Delta T$ data.

Table 4 shows the daily selection and the simple probabilities of $P_{1}$ and $P_{0}$ (the probability of a day without any sea breeze; $P_{0}=[0] / N$ or $1-P_{1}$ ) computed by the proposed manual selection (M) and the independent RCG method for the 4-month period. A very close connection in $P_{1}$ takes place in January (M 38.7\% and RCG 41.9\%) because reversal in WD from land to sea breezes is easily identified. The connection in $P_{1}$ slightly decreases in April 


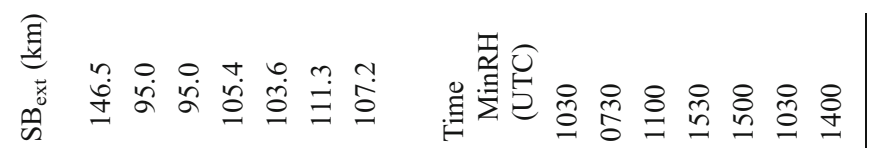

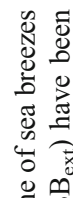

हृ

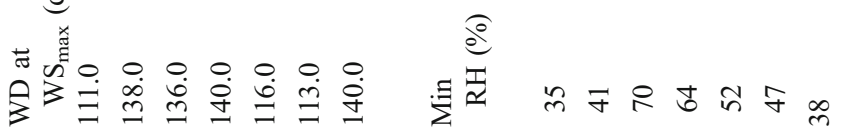

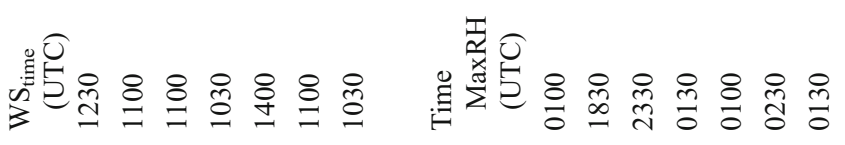

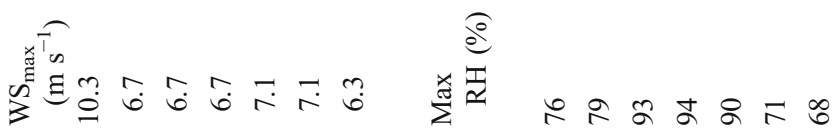

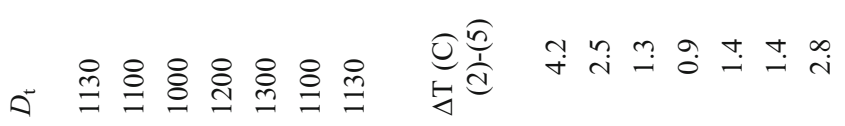

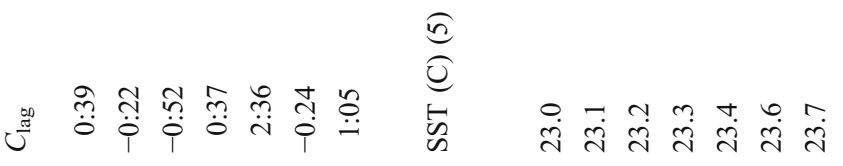

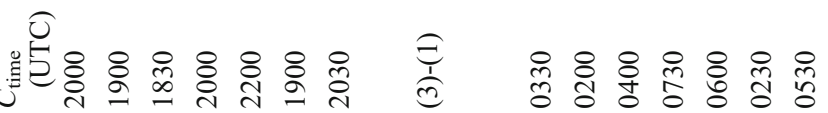

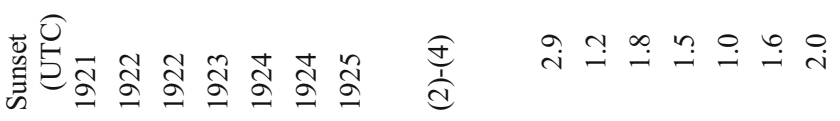

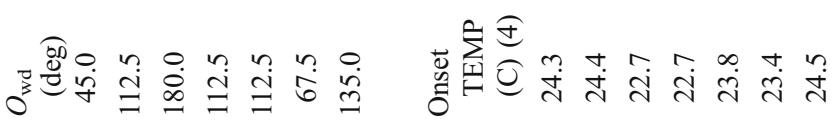

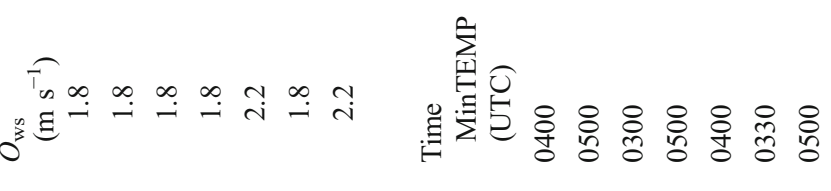

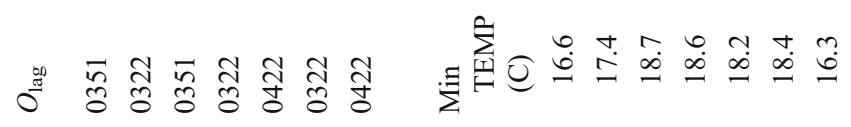

O) $\quad \sum_{i=1}^{+} 0$

\section{$\sum_{\substack{x \\ 0}}^{\infty}$}

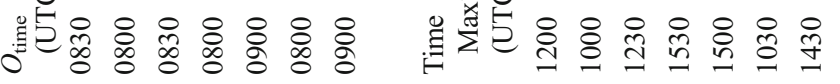

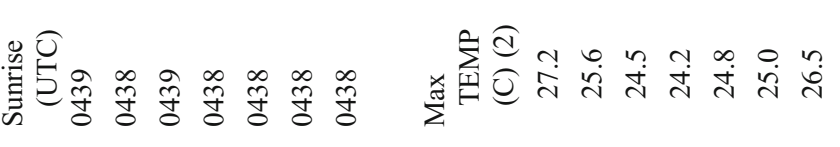

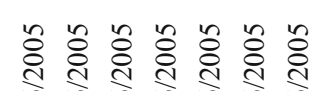

芴 要

里

过

国

ธิ

恶

记

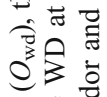

总

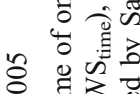

穴刍这.

志导 离

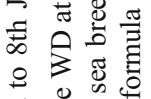

ป

产

눌

矛

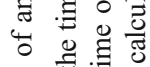

死志势

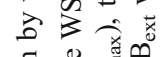

है

के क्ष

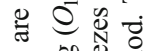

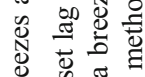

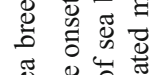

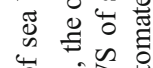

药

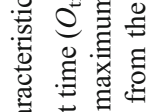

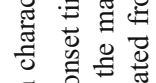

बี

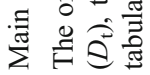


Table 4 Comparison between sea breeze (1) and non-sea breeze (0) episodes found by the manual algorithm (M) and the RCG selection technique for the 4-month period in 2004

\begin{tabular}{|c|c|c|c|c|c|c|c|c|}
\hline \multirow[t]{2}{*}{ Day } & \multicolumn{2}{|c|}{ January } & \multicolumn{2}{|l|}{ April } & \multicolumn{2}{|l|}{ July } & \multicolumn{2}{|c|}{ November } \\
\hline & $\mathrm{M}$ & $\mathrm{RCG}$ & M & $\mathrm{RCG}$ & $\mathrm{M}$ & RCG & M & $\mathrm{RCG}$ \\
\hline 1 & 0 & 0 & 0 & 1 & 1 & 1 & 0 & 0 \\
\hline 2 & 0 & 0 & 0 & 0 & 1 & 1 & 0 & 0 \\
\hline 3 & 1 & 1 & 1 & 1 & 1 & 0 & 0 & 1 \\
\hline 4 & 1 & 1 & 1 & 1 & 1 & 0 & 0 & 1 \\
\hline 5 & 1 & 1 & 1 & 1 & 1 & 1 & 0 & 1 \\
\hline 6 & 1 & 1 & 1 & 1 & 0 & 0 & 0 & 0 \\
\hline 7 & 1 & 1 & 1 & 0 & 0 & 1 & 0 & 1 \\
\hline 8 & 0 & 0 & 0 & 0 & 0 & 0 & 1 & 1 \\
\hline 9 & 0 & 0 & 0 & 1 & 1 & 1 & 0 & 0 \\
\hline 10 & 0 & 0 & 0 & 1 & 1 & 1 & 0 & 0 \\
\hline 11 & 1 & 1 & 0 & 0 & 1 & 1 & 0 & 1 \\
\hline 12 & 0 & 0 & 0 & 1 & 0 & 0 & 0 & 0 \\
\hline 13 & 0 & 0 & 1 & 1 & 1 & 1 & 0 & 0 \\
\hline 14 & 0 & 0 & 0 & 1 & 1 & 1 & 1 & 1 \\
\hline 15 & 1 & 0 & 0 & 0 & 1 & 1 & 1 & 1 \\
\hline 16 & 0 & 0 & 0 & 0 & 1 & 0 & 1 & 1 \\
\hline 17 & 0 & 0 & 0 & 1 & 1 & 1 & 1 & 1 \\
\hline 18 & 0 & 0 & 0 & 0 & 1 & 1 & 1 & 0 \\
\hline 19 & 1 & 1 & 0 & 0 & 1 & 1 & 1 & 1 \\
\hline 20 & 0 & 0 & 0 & 0 & 1 & 1 & 1 & 1 \\
\hline 21 & 1 & 1 & 1 & 1 & 1 & 1 & 1 & 1 \\
\hline 22 & 1 & 1 & 0 & 0 & 1 & 1 & 1 & 1 \\
\hline 23 & 0 & 0 & 1 & 1 & 1 & 1 & 1 & 1 \\
\hline 24 & 0 & 0 & 1 & 1 & 1 & 1 & 1 & 1 \\
\hline 25 & 0 & 1 & 1 & 1 & 1 & 0 & 1 & 1 \\
\hline 26 & 0 & 0 & 1 & 1 & 1 & 0 & 1 & 1 \\
\hline 27 & 0 & 0 & 1 & 0 & 1 & 1 & 1 & 1 \\
\hline 28 & 0 & 0 & 0 & 1 & 1 & 0 & 1 & 1 \\
\hline 29 & 0 & 1 & 0 & 1 & 1 & 1 & 0 & 1 \\
\hline 30 & 1 & 1 & 0 & 0 & 1 & 1 & 0 & 0 \\
\hline 31 & 1 & 1 & - & - & 1 & 1 & - & - \\
\hline SB days & 12 & 13 & 12 & 18 & 27 & 22 & 16 & 21 \\
\hline$P_{1}(\%)$ & 38.7 & 41.9 & 40.0 & 60.0 & 87.1 & 71.0 & 53.3 & 70.0 \\
\hline$P_{0}(\%)$ & 61.3 & 58.1 & 60.0 & 40.0 & 12.9 & 29.0 & 46.7 & 30.0 \\
\hline $\mathrm{PSB}_{\mathrm{p}} \mathrm{SB}_{\mathrm{i}}$ & 0.79 & & 0.50 & & 0.75 & & 0.68 & \\
\hline $\mathrm{PNSB}_{\mathrm{p}} \mathrm{NSB}_{\mathrm{i}}$ & 0.85 & & 0.50 & & 0.30 & & 0.53 & \\
\hline $\mathrm{PSB}_{\mathrm{p}} \mathrm{NSB}_{\mathrm{i}}$ & 0.33 & & 0.20 & & 0.86 & & 0.14 & \\
\hline $\mathrm{PNSB}_{\mathrm{p}} \mathrm{SB}_{\mathrm{i}}$ & 0.67 & & 0.80 & & 0.14 & & 0.86 & \\
\hline
\end{tabular}

The last seven rows display the number of sea breeze days; the simple probabilities $P_{1}$ and $P_{0}$; and the probabilities $\mathrm{PSB}_{\mathrm{p}} \mathrm{SB}_{\mathrm{i}}, \mathrm{PNSB}_{\mathrm{p}} \mathrm{NSB}_{\mathrm{i}}$, $\mathrm{PSB}_{\mathrm{p}} \mathrm{NSB}_{\mathrm{i}}$ and $\mathrm{PNSB}_{\mathrm{p}} \mathrm{SB}_{\mathrm{i}}$

(M 40.0\% and RCG 60.0\%), July (M 87.1\% and RCG $71.0 \%$ ) and November (M 53.3\% and RCG 70.0\%) as reversal in WD associated with sea breezes is less discernible. For instance, the $\mathrm{PSB}_{\mathrm{p}} \mathrm{SB}_{\mathrm{i}}$ and the $\mathrm{PNSB}_{\mathrm{p}} \mathrm{NSB}_{\mathrm{i}}$ stands at 0.79 and 0.85 in January, respectively. Sea breezes and large-scale flows are easily distinguished in winter months. A higher rate of success was found in $\mathrm{PSB}_{\mathrm{p}} \mathrm{SB}_{\mathrm{i}}$ in July with 0.75 , whereas the $\mathrm{PNSB}_{\mathrm{p}} \mathrm{NSB}_{\mathrm{i}}$ is not high with 0.30 because the RCG method rejects sea breeze days without land breezes the night before. The comparison is 
quite acceptable for April and November months, with a $\mathrm{PSB}_{\mathrm{p}} \mathrm{SB}_{\mathrm{i}}$ of 0.50 and 0.68 and a $\mathrm{PNSB}_{\mathrm{p}} \mathrm{NSB}_{\mathrm{i}}$ of 0.50 and 0.53 , respectively. The different detections between both manual methods, i.e. number of days set within $\mathrm{SB}_{\mathrm{p}} \mathrm{NSB}_{\mathrm{i}}$ and $\mathrm{NSB}_{\mathrm{p}} \mathrm{SB}_{\mathrm{i}}$, represents $<1 / 3$ of days for each month: January (three cases), April (ten cases), July (seven cases) and November (seven cases). We generally found that the RCG method tends to overestimate the number of sea

Table 5 Comparison between sea breeze (1) and non-sea breeze (0) episodes found by the automated algorithm (A) and the PG selection technique for the 4-month period in 2004

\begin{tabular}{|c|c|c|c|c|c|c|c|c|}
\hline \multirow[t]{2}{*}{ Day } & \multicolumn{2}{|c|}{ January } & \multicolumn{2}{|l|}{ April } & \multicolumn{2}{|l|}{ July } & \multicolumn{2}{|c|}{ November } \\
\hline & A & PG & A & PG & & A & PG & A \\
\hline 1 & 0 & 0 & 0 & 1 & 1 & 1 & 0 & 0 \\
\hline 2 & 0 & 0 & 0 & 0 & 0 & 0 & 0 & 0 \\
\hline 3 & 1 & 0 & 1 & 1 & 1 & 0 & 0 & 0 \\
\hline 4 & 1 & 0 & 1 & 0 & 1 & 0 & 0 & 0 \\
\hline 5 & 1 & 0 & 0 & 0 & 1 & 1 & 0 & 0 \\
\hline 6 & 1 & 0 & 0 & 1 & 0 & 0 & 0 & 0 \\
\hline 7 & 0 & 0 & 1 & 1 & 0 & 1 & 0 & 0 \\
\hline 8 & 0 & 0 & 0 & 0 & 0 & 0 & 0 & 0 \\
\hline 9 & 0 & 0 & 0 & 0 & 0 & 0 & 0 & 0 \\
\hline 10 & 0 & 0 & 0 & 0 & 0 & 0 & 0 & 0 \\
\hline 11 & 1 & 0 & 0 & 0 & 0 & 0 & 0 & 0 \\
\hline 12 & 0 & 0 & 0 & 0 & 0 & 0 & 0 & 0 \\
\hline 13 & 0 & 1 & 1 & 0 & 0 & 0 & 0 & 0 \\
\hline 14 & 0 & 0 & 0 & 0 & 0 & 0 & 1 & 0 \\
\hline 15 & 0 & 0 & 0 & 0 & 0 & 0 & 0 & 0 \\
\hline 16 & 0 & 0 & 0 & 0 & 1 & 0 & 0 & 0 \\
\hline 17 & 0 & 0 & 0 & 0 & 1 & 0 & 0 & 0 \\
\hline 18 & 0 & 0 & 0 & 0 & 1 & 0 & 0 & 0 \\
\hline 19 & 0 & 0 & 0 & 0 & 1 & 0 & 0 & 1 \\
\hline 20 & 0 & 0 & 0 & 0 & 1 & 0 & 1 & 1 \\
\hline 21 & 1 & 0 & 0 & 1 & 0 & 0 & 0 & 0 \\
\hline 22 & 1 & 0 & 0 & 0 & 1 & 0 & 0 & 0 \\
\hline 23 & 0 & 0 & 1 & 1 & 0 & 1 & 1 & 1 \\
\hline 24 & 0 & 0 & 1 & 1 & 0 & 1 & 1 & 1 \\
\hline 25 & 0 & 0 & 0 & 1 & 0 & 1 & 1 & 0 \\
\hline 26 & 0 & 0 & 0 & 1 & 1 & 0 & 1 & 0 \\
\hline 27 & 0 & 0 & 0 & 1 & 1 & 1 & 0 & 0 \\
\hline 28 & 0 & 1 & 0 & 0 & 0 & 0 & 0 & 0 \\
\hline 29 & 0 & 0 & 0 & 0 & 0 & 0 & 0 & 0 \\
\hline 30 & 1 & 0 & 0 & 0 & 1 & 0 & 0 & 0 \\
\hline 31 & 0 & 0 & 0 & 0 & 1 & 1 & 0 & 0 \\
\hline SB days & 8 & 2 & 6 & 10 & 14 & 8 & 6 & 4 \\
\hline$P_{1}(\%)$ & 25.8 & 6.5 & 20.0 & 33.3 & 45.2 & 25.8 & 20.0 & 13.3 \\
\hline$P_{0}(\%)$ & 74.2 & 93.5 & 80.0 & 66.7 & 54.8 & 74.2 & 80.0 & 86.7 \\
\hline $\mathrm{PSB}_{\mathrm{p}} \mathrm{SB}_{\mathrm{i}}$ & 0.00 & & 0.33 & & 0.22 & & 0.43 & \\
\hline $\mathrm{PNSB}_{\mathrm{p}} \mathrm{NSB}_{\mathrm{i}}$ & 0.68 & & 0.70 & & 0.48 & & 0.86 & \\
\hline $\mathrm{PSB}_{\mathrm{p}} \mathrm{NSB}_{\mathrm{i}}$ & 0.80 & & 0.25 & & 0.71 & & 0.75 & \\
\hline $\mathrm{PNSB}_{\mathrm{p}} \mathrm{SB}_{\mathrm{i}}$ & 0.20 & & 0.75 & & 0.29 & & 0.25 & \\
\hline
\end{tabular}

The last seven rows display the number of sea breeze days; the simple probabilities $P_{1}$ and $P_{0}$; and the probabilities $\mathrm{PSB}_{\mathrm{p}} \mathrm{SB}_{\mathrm{i}}, \mathrm{PNSB}_{\mathrm{p}} \mathrm{NSB}_{\mathrm{i}}$, $\mathrm{PSB}_{\mathrm{p}} \mathrm{NSB}_{\mathrm{i}}$ and $\mathrm{PNSB}_{\mathrm{p}} \mathrm{SB}_{\mathrm{i}}$ 
breeze days more than our manual technique in January $\left(\mathrm{PNSB}_{\mathrm{p}} \mathrm{SB}_{\mathrm{i}}\right.$ 0.67), April (0.80) and November (0.86), except in July, when our manual selection method overestimates them $\left(\mathrm{PSB}_{\mathrm{p}} \mathrm{NSB}_{\mathrm{i}}\right.$ 0.86), because it takes sea breeze episodes without nocturnal offshore winds into account. To conclude, the comparison showed that our manual selection is capable of extracting a good dataset.

Moreover, the accuracy of the automated selection method was evaluated by comparison with the sea breeze methodology put forward by Prtenjak and Grisogono (2007) (hereinafter PG technique) for studying sea/land breeze climatological characteristics along the northern Croatian Adriatic coast. We first considered the automated method proposed by Borne et al. (1998), but finally, the PG technique was chosen for the comparison because it is based on the same surface measurements as our automated selection method, with the exception of the cloudiness filter. A detailed description of the five test criteria of the PG method can be found in Prtenjak and Grisogono (2007).

Table 5 shows the daily results and $P_{1}$ and $P_{0}$ computed by the proposed automated method (A) and the independent PG technique for the 4-month period. It was found that the occurrence of sea breezes is underestimated in comparison with the detections of the manual methodologies. It should be noted that the empirical probability $P_{1}$ drastically drops from manual to automated selection methods: January (A $25.8 \%$ and PG 6.5\%), April (A 20.0\% and PG 33.3\%), July (A $45.2 \%$ and PG 25.8\%) and November (A 20.0\% and PG $13.3 \%)$. The high $P_{0}$ values for both algorithms, ranging from $50 \%$ to $100 \%$, confirm that automated selection techniques greatly underestimate the occurrence of sea breezes. Evaluation of the accuracy using the probabilities summarised above (Eqs. 4-7) reveals that sea breeze datasets depend on the nature of test criteria and thresholds identified. Compared with the PG technique, our A method yielded 0.0 hindcast accuracy $\left(\mathrm{PSB}_{\mathrm{p}} \mathrm{SB}_{\mathrm{i}}\right)$ in January, 0.33 in April, 0.22 in July and 0.43 in November. In contrast, the $\mathrm{PNSB}_{\mathrm{p}} \mathrm{NSB}_{\mathrm{i}}$ is rather high, with 0.68 in January, 0.70 in April, 0.48 in July and 0.86 in November. This is also due to the fact that automated algorithms reject many true sea breeze episodes. The different detections between both automated selection techniques, i.e. number of days set within $\mathrm{SB}_{\mathrm{p}} \mathrm{NSB}_{\mathrm{i}}$ and $\mathrm{NSB}_{\mathrm{p}} \mathrm{SB}_{\mathrm{i}}$, is somewhat greater than manual algorithms: January (10 cases), April ( 8 cases), July (14 cases) and November (4 cases). Our automated method is less demanding and the $\mathrm{SB}_{\mathrm{p}} \mathrm{NSB}_{\mathrm{i}}$ is greater in January (0.80), July (0.71) and November (0.75). However, the PG method selects more sea breeze episodes in April and the $\mathrm{NSB}_{\mathrm{p}} \mathrm{SB}_{\mathrm{i}}$ is therefore 0.75 , which might be related to the biggest $\Delta T$ throughout the year (Fig. 4). A detailed examination of the filters employed by the PG method revealed that filter $\mathrm{V}$, which uses a $\Delta T$ threshold of $>3^{\circ} \mathrm{C}$, rejects $80 \%$ (January), 9.1\% (April), 68.0\% (July) and $66.7 \%$ (November) of sea breeze episodes detected by filters 1 to 4 . To conclude, automated algorithms create a set of true sea breeze events that clearly depend upon the test criteria used and underestimate the occurrence of this local wind.

\section{Summary and concluding remarks}

We simultaneously developed and evaluated an automated and manual selection method in order to identify past sea breeze events and to increase our knowledge of this local wind in the Bay of Alicante (Spain). A reasonably accurate subset of 475 and 1414 sea breeze days created for the 6-year study period (2000-2005), as along with a large sea breeze database (key variables measured during sea breeze occurrences), are presented for any coastal researcher interested in numerical-theoretical (model validation of different sea breeze episodes), observational-experimental and climatological sea breeze studies. These available sea breeze databases are the major contribution of the paper. Comprehensive datasets are crucial, for instance, for model verification (Mizuma 1995).

Evaluation of both techniques demonstrates that the sea breeze datasets constructed are clearly dependent on the nature of the test criteria employed by each researcher, which is extremely dependent on the measurements available. The main finding is that the manual selection technique enables the occurrence and persistence of sea breezes to be studied (Azorin-Molina and Martin-Vide 2007) because the subjective revision considers sea breeze episodes in complete and incomplete diurnal cycles. In contrast, the automated selection method only distinguishes true sea breeze events and is therefore capable of compiling the climatology of the main characteristics and physical factors controlling sea breezes (Azorin-Molina and Chen 2009; Azorin-Molina et al. 2009, 2011).

To conclude, there is a need for an accurate automated selection method that makes use of a minimum number of variables and can be easily applied to any coastal region in the world. An automated selection filter based on regional sea level pressure difference was recently proposed by Azorin-Molina and Lopez-Bustins (2008).

Acknowledgements The University Institute CEAM-UMH is financed by the Generalitat Valenciana. This research was supported by the Spanish Ministerio de Ciencia e Innovación (MICINN) in the frame of the CONSOLIDER-INGENIO 2010 Programme (GRACCIE project) and by the Torres Quevedo Program (PTQ-08-02-06762). The authors would like to thank the Institute of Coastal Ecology of El Campello for providing the sea surface temperature data; the AEMET for cloudiness data; and especially to Katarina Borne for the great effort she made with the manual selection of sea breezes. 


\section{References}

Arritt RW (1987) The effect of water surface temperature on lake breezes and thermal internal boundary layers. Bound-Layer Meteor 40:101-125. doi:10.1007/BF00140071

Azorin-Molina C (2007) A climatological study of sea breezes in Alicante. Sea breeze fronts over the Iberian Mediterranean area and the isle of Mallorca. University Institute of Geography, University of Alicante, Alicante, Spain, p 288

Azorin-Molina C, Chen D (2009) A climatological study of the influence of synoptic-scale flows on sea breeze evolution in the Bay of Alicante (Spain). Theor Appl Climatol 96:249-260. doi:10.1007/s00704-008-0028-2

Azorin-Molina C, Lopez-Bustins JA (2008) An automated sea breeze selection technique based on regional sea-level pressure difference: WeMOi. Int J Climatol 28:1681-1692. doi:10.1002/ joc. 1663

Azorin-Molina C, Martin-Vide J (2007) Methodological approach to the study of the daily persistence of the sea-breeze in Alicante (Spain). Atmosfera 20:57-81

Azorin-Molina C, Sanchez-Lorenzo A, Calbo J (2009) A climatological study of sea breeze clouds in the southeast of the Iberian Peninsula (Alicante, Spain). Atmosfera 22:33-49

Azorin-Molina C, Chen D, Tijm S, Baldi M (2011) A multi-year study of sea breezes in a Mediterranean coastal site: Alicante (Spain). Int J Climatol 31:468-486. doi:10.1002/joc.2064

Banfield CE (1991) The frequency and surface characteristics of sea breezes at St. Johns, Newfoundland. Climatol Bull 25:3-20

Barbato JP (1978) Areal parameters of the sea breeze and its vertical structure in the Boston basin. Bull Am Meteorol Soc 59:1420 1431. doi:10.1175/1520-0477(1978) $059<1420$ :APOTSB $>2.0$. $\mathrm{CO} ; 2$

Biggs WG, Graves ME (1962) A lake breeze index. J Appl Meteorol 1:474-480. doi:10.1175/1520-0450(1962) 001<0474:ALBI $>2.0$. $\mathrm{CO} ; 2$

Borne K, Chen D, Nunez M (1998) A method for finding sea breeze days under stable synoptic conditions and its application to the Swedish west coast. Int J Climatol 18:901-914. doi:10.1007/ s10546-007-9185-6

Bowers LA (2004) The effect of sea surface temperature on sea breeze dynamics along the coast of New Jersey. Graduate School-New Brunswick Rutgers, The State University of New Jersey, New Brunswick

Brittain DW (1978) Forecasting sea-breezes at Eskmeals. Meteorol Mag 107:88-96

Crosman ET, Horel JD (2010) Sea and lake breezes: a review of numerical studies. Bound-Layer Meteor 137:1-29. doi:10.1007/ s10546-010-9517-9

Frysinger JR, Lindner BL, Brueske SL (2003) A statistical sea-breeze prediction algorithm for Charleston, South Carolina. Weather Forecast 18:614-625. doi:10.1175/1520-0434(2003) 018<0614: ASSPAF $>2.0 . \mathrm{CO} ; 2$

Furberg M, Steyn DG, Baldi M (2002) The climatology of sea breezes on Sardinia. Int J Climatol 22:917-932. doi:10.1002/joc.780

González J, Guijarro JA, Jansà A (1998) Caracterización de la brisa en Mallorca. In $1^{\text {a }}$ Asamblea Hispano-Portuguesa de Geodesia y Geofísica. 9 ${ }^{a}$ Asamblea española de Geodesia y Geofísica, Aguadulce

Gustavsson T, Lindqvist S, Borne K, Bogren J (1995) A study of sea and land breezes in an archipelago on the west coast of Sweden. Int J Climatol 15:785-800. doi:10.1002/joc.3370150706

Hall CD (1954) Forecasting the lake breeze and its effects on visibility at Chicago Midway Airport. Bull Am Meteorol Soc 35:105-111
Hewson EW, Moroz WJ (1966) The mesoscale interaction of a lake breeze and a low level outflow from a thunderstorm. J Appl Meteorol 5:148-155

Laird NF, Kristovich DAR, Liang X-Z, Arritt RW, Labas K (2001) Lake Michigan lake breezes: climatology, local forcing, and synoptic environment. J Appl Meteorol 40:409-424. doi:10.1007/s10546-007-9185-6

Lyons WA (1972) The climatology and prediction of the Chicago lake breeze. J Appl Meteorol 11:1259-1270

Miao J-F, Kroon LJM, Vilà-Guerau de Arellano J, Holtslag AAM (2003) Impacts of topography and land degradation on the sea breeze over eastern Spain. Meteorol Atmos Phys 84:157-170. doi:10.1007/s00703-002-0579-1

Millán M (2002) Ozone dynamics in the Mediterranean basin. A collection of scientific papers resulting from the MECAPIP, RECAPMA and SECAP projects. Air pollution Research Report 78, Fundación Centro de Estudios Ambientales del Mediterráneo (CEAM), Valencia

Miller STK, Keim BD (2003) Synoptic-scale controls on the sea breeze of the central New England Coast. Weather Forecast $18: 236-248$

Mizuma M (1995) General aspects of land and sea breezes in Osaka Bay and surrounding area. J Meteorol Soc Jpn 73:1029-1040

Neumann J (1984) The Coriolis force in relation to the sea and land breezes. A historial note. Bull Am Meteorol Soc 65:24-26

Olcina-Cantos J, Azorin-Molina C (2004) The meteorological importance of sea breezes in the Levant region of Spain. Weather 59:282-286. doi:10.1256/wea.176.03

Porson A, Steyn DG, Schayes G (2007) Formulation of an index for sea breezes in opposing winds. J Appl Meteor Climatol 46:12571263. doi:10.1175/JAM2525.1

Prezerakos NG (1986) Characteristics of the sea breeze in Attica, Greece. Bound-Layer Meteor 36:245-266. doi:10.1007/BF00118663

Prtenjak MT, Grisogono B (2007) Sea/land breeze climatological characteristics along the northern Croatian Adriatic coast. Theor Appl Climatol 91:1-15. doi:10.1007/BF00118663

Ramis C, Jansá A, Alonso S (1990) Sea breeze in Mallorca. A numerical study. Meteorol Atmos Phys 42:249-258. doi:10.1007/ BF01314828

Redaño A, Cruz J, Lorente J (1991) Main features of the sea breeze in Barcelona. Meteorol Atmos Phys 46:175-179. doi:10.1007/ BF01027342

Ryznar E, Touma JS (1981) Characteristics of true lake breezes along the eastern shore of Lake Michigan. Atmos Environ 15:1201-1205

Salvador R, Millán M (2003) Análisis histórico de las brisas en Castellón. Tethys 2:37-51

Segal M, Pielke RA (1985) The effect of water temperature and synoptic winds on the development of surface flows over narrow, elongated water bodies. J Geophys Res 90:4907-4910. doi:10.1029/JC090iC03p04907

Simpson JE (1994) Sea breeze and local wind. Cambridge University Press, Cambridge, p 234. doi:10.2277/0521452112

Steyn DG (2003) Scaling the vertical structure of sea breezes revisited. Bound-Layer Meteor 107:177-188. doi:10.1023/ A:1021568117280

Steyn DG, Faulkner DA (1986) The climatology of sea breezes in the Lower Fraser Valley. BC Climatol Bull 20:21-39

Tijm ABC (1999) Sea-breeze studies. Faculteit der Natuur, University of Utrecht, Universal Press, Utrecht, p 154

Tijm ABC, Van Delden AJ (1999) The role of sound waves in seabreeze initiation. Quart J Roy Meteor Soc 125:1997-2018. doi:10.1002/qj.49712555805

Van Delden AJ (1993) Observational evidence of the wave-like character of the sea breeze effect. Beitr Phys Atmos 66:63-72 